\title{
Why are emerging countries popular for clinical research?
}

\author{
V Strüver, ${ }^{1} \mathrm{MSc}$; S C Ibeneme, ${ }^{2,3} \mathrm{PhD}$ \\ ${ }^{1}$ Hochschule Hannover - University of Applied Sciences and Arts, Faculty III - Media, Information, and Design, Hanover, Germany \\ ${ }^{2}$ Department of Medical Rehabilitation, Faculty of Health Sciences, Enugu Campus, University of Nigeria, Enugu, Nigeria \\ ${ }^{3}$ Department of Physiotherapy, School of Therapeutic Studies, Faculty of Health Sciences, University of the Witwatersrand, Johannesburg, \\ South Africa
}

Corresponding author: V Strüver (vanessa.struever@hs-hannover.de)

\begin{abstract}
Background. The business of clinical research has changed in the past two decades, shifting from industrialised Western countries to so-called emerging markets such as Eastern Europe, Latin America and Africa. An appraisal of the trends could identify associated factors that may have implications for the local populations and their endemic diseases.

Objectives. To identify potential reasons why emerging countries have become attractive places for international sponsors to conduct their clinical trials.

Methods. Using ClinicalTrials.gov, the Pan African Clinical Trials Registry, the National Health Research Database and the Nigeria Clinical Trials Registry, trend data on clinical research development were determined for two emerging African markets, Nigeria and South Africa (SA), from 2010 to 2018. Also, health data on the two countries from the fact sheets of health statistics of the World Health Organization were compared, as well as regulatory and ethical conditions. Available data were analysed using descriptive statistics and trend analysis.

Results. The impact of globalisation is evident from the upward trend in clinical trials in SA before 2010, and the clear downward trend thereafter. One reason for this change could be the alignment of SA's regulatory and ethical frameworks with the Western world. In contrast, the upward trend is only just beginning in Nigeria, with the introduction of ethical/regulatory frameworks, and supportive institutions making the business of clinical research more attractive on an international level. Although the number of international and local sponsors increased in Nigeria from 2010 to 2018, only the latter increased in SA, with the former decreasing over the same period. Overall, there is a mismatch between country-specific diseases and the drugs being tested, to the extent that leprosy, which is endemic in Nigeria, and tuberculosis in SA were not in the list of top 10 study areas in either country.

Conclusions. The globalisation trend is evident in the clinical trials business, but cannot be generalised to all emerging countries. Timing and intensity vary from country to country relative to factors that advance the existing profit-orientated business models of the sponsors. Furthermore, various diseases have been localised, which entails a diversely increasing need for research.
\end{abstract}

S Afr Med J 2021;111(5):453-459. https://doi.org/10.7196/SAMJ.2021.v111i5.14870

In the globalisation process, the business of clinical research has increased worldwide. While clinical trials have mainly been conducted in North America, Western Europe and Australia, the globalisation trend has led to a shift to the so-called emerging markets during the past two decades. ${ }^{[1]}$ These markets are 'emerging regions of Eastern Europe, Latin America, Asia, the Middle East, and Africa. ${ }^{[2]}$ While a significant increase in clinical trials in emerging countries has been observed, there has been a reduction in the proportion of clinical trials in North America and Western Europe ${ }^{[3]}$ Considering the poor economic conditions in emerging countries, what makes them so interesting for sponsors of clinical trials?

Ten years ago, more than $80 \%$ of the clinical trials listed in the ClinicalTrials.gov registry were conducted in the developed world, while developing countries were under-represented in clinical research. Reports now suggest that interest of international sponsors in the developing markets is buoyed by several factors associated with the profit-orientated business model of the multinational pharmaceutical industry ${ }^{[4,5]}$ and by the impact of globalisation, which favours export of business to locations where, among other costcontainment opportunities, labour is cheap, doing business is easy, regulatory mechanisms are poor and costs are low. Internationally sponsored clinical research is therefore moving to countries where the research industry will get the best value for money while gathering data acceptable for submission to regulatory agencies. ${ }^{[6]}$ The shift in the global clinical trials arena may therefore not necessarily result from a primary interest in addressing the local health needs of the populations in which the trials are conducted, and there may well be a mismatch between local health needs and the research interest of the sponsors of the clinical trials. Several past events have given credence to these views, including the infamous Pfizer clinical trials of Trovan for cerebral meningitis in the naive and poverty-stricken population of Tudun Wada, Kano State, Nigeria, which had many negative outcomes and for which Pfizer was indicted. ${ }^{[7]}$ This example shows that some clinical trials classified as undesirable in developed countries can be conducted in developing countries where legal requirements are different. ${ }^{[7]}$ In Europe, Pfizer's licence for Trovan was withdrawn owing to several deaths and cases of liver toxicity. In Nigeria, however, the clinical trial could be conducted without valid approval from an ethics committee..$^{[7]}$

Nevertheless, the increasing presence of internationally sponsored clinical trials in developing countries reflects the fact that these countries now 'represent important growth areas for pharmaceutical companies and clinical research organisations. ${ }^{\text {[6] }}$ It also indicates growing confidence that the health infrastructure in developing countries can reliably match the standards needed to comply with the requirements of the International Council for Harmonisation of Technical Requirements for Pharmaceuticals for Human Use (ICH) ${ }^{[6]}$ There is therefore a need to identify the reasons behind 
the current interests of sponsors of clinical trials in the developing market as a critical step in evaluating how such interests align with the health needs of the local population, and whether the ICH ethical principles of beneficence and social justice are followed when conducting human clinical trials. Certain important questions arise that may provide insight into the factors driving the current global shift of clinical trials from the North to the South, such as:

- Can the globalisation trend be observed in the clinical trial arena in emerging African markets? This article will examine Nigeria and South Africa (SA) specifically.

- Are there possible factors that may influence the clinical research business in Nigeria and SA?

- Do most of the drugs being tested in Nigeria and SA address the common endemic diseases prevalent in those areas?

- Further insights need to be provided on differences between local and international sponsors, both in the number of clinical trials and in the indications for these trials.

\section{Objectives}

The overall objective of this study was to identify the reasons why sponsors increasingly conduct their clinical trials in emerging markets. Data on the number of clinical trials in all African countries during the period 2010 - 2018 were therefore collected from ClinicalTrials.gov, the Pan African Clinical Trials Registry, the National Health Research Database and the Nigeria Clinical Trials Registry. We also documented whether these studies were financed by national or international sponsors, and to what extent diseases related to local medical needs were considered. Data extraction was supplemented by data on the regulatory framework and the process of and requirements for ethical approval of a clinical trial in the selected countries. This was done to investigate any possible impact related to the research question.

\section{Methods}

\section{Country selection}

For appropriate country selection for the research question, it was necessary to clarify how emerging countries are defined. For this purpose, the Development Assistance Committee (DAC) list of the Official Development Assistance recipients of the Organisation for Economic Co-operation and Development, effective for reporting on 2011 flows, was applied. ${ }^{[8]}$ According to this list, emerging countries are defined as countries with a lower-middle income of USD1 006 3975 gross national income per capita in 2010 or an upper-middle income of USD3 976 - 12 275. The country selection was limited to the African continent because Africa has the highest disease burden in the world and a large number of African countries are defined as emerging countries in the DAC list and were consequently of specific interest to the authors. ${ }^{[9-10]}$

One country was selected for each of the above income categories. $\mathrm{SA}$, an example of an emerging market with an upper-middle income, is a country of $\sim 50$ million population with the most sophisticated and productive economy in sub-Saharan Africa. It has a gross domestic product (GDP) of USD368 billion, and has been an active player in the clinical trials industry for over four decades. ${ }^{[11,12]}$ In contrast, Nigeria, although the largest economy in Africa, is an example of an emerging market with a lower-middle income. It has a population of nearly 200 million and labour is cheap, yet the economy is weak and undiversified, and there is a high disease burden in a mostly naive population with extreme variations in level of education. Nigeria was not a destination for clinical trials until the current era of globalisation. ${ }^{[13,14]}$ The latest re-basing of the economy in 2015 improved the estimated GDP to nearly USD500 billion, making Nigeria the 26th largest economy in the world. ${ }^{[13-15]}$
Overall, country selection in this study was based on availability of data on the research questions and the connection to local research partners.

\section{A search of clinical trial databases}

To provide a comprehensive overview of clinical trials ever conducted or ongoing in African countries, a corresponding database query was conducted in the ClinicalTrials.gov registry of the US National Library of Medicine at the National Institutes of Health ${ }^{[16]}$ as well as in the Pan African Clinical Trials Registry. ${ }^{[17]}$ Subsequently, trend data from ClinicalTrials.gov were determined covering the period 2010 - 2018 for the selected countries, SA and Nigeria. In parallel, the National Health Research Database of the SA National Department of Health $(\mathrm{NDoH})^{[18]}$ and the Nigeria Clinical Trials Registry of the Federal Ministry of Health ${ }^{[19]}$ were also used to obtain trend data. From information on ClinicalTrials.gov, the indication area and the sponsor type (local or international) were determined. A distinction was made between the two financing types, i.e. international or national sponsors.

\section{Health statistics of the World Health Organization and local regulatory and ethical guidelines}

Health data for 2013 and 2015 on the selected countries, SA and Nigeria, were extracted from the 2016 fact sheets of health statistics of the World Health Organization (WHO). ${ }^{[20,21]}$ Similarly, 2012 disease incidence and prevalence rates were used for this research and served as the starting point for investigation of the extent to which clinical trials were able to meet indications with a particular local medical significance. The data extraction was supplemented by data on the regulatory framework and the process and requirements for ethical approval of a clinical trial in both selected countries. This was considered necessary to investigate any possible impact related to the research question. The South African Good Clinical Practice Guidelines of the $\mathrm{NDoH}^{[22]}$ as well as the SA ClinRegs website of the National Institute of Allergy and Infectious Diseases of the National Institute of Health ${ }^{[23]}$ and the Guidelines for Clinical Trial Application in Nigeria of the National Agency for Food and Drug Administration and Control (NAFDAC) in Nigeria ${ }^{[24]}$ were used to compare the framework conditions of the national authorities. In addition to analysing the legal framework for the national authorities, the ethical frameworks of the national ethics committees were compared. The document Ethics in Health Research - Principles, Processes and Structures of the $\mathrm{NDoH}$ in $\mathrm{SA}^{[25]}$ and the National Code of Health Research Ethics of the Federal Ministry of Health in Nigeria ${ }^{[26]}$ were used as source documents.

\section{Data analysis}

Data collected on sponsorship were used to investigate whether there were differences between local and international sponsors, both in the number of clinical trials and in the indication areas. Available data from Nigeria and SA were analysed and characterised separately using SPSS software version 26 (IBM, USA). The outcome of interest was the number of clinical trials related to indication areas. The data were evaluated using descriptive statistics and trend analysis.

\section{Results}

Search results

The ranking of all African countries according to the number of all registered clinical trials in ClinicalTrials.gov (Table 1) up to 2018 shows that SA, with a total of 2545 registered trials, was the country with the second-highest number of trials on the African continent after Egypt, while Nigeria was ranked 10th, with 145 registered 
clinical trials. In comparison, the ranking of all African countries that have registered clinical trials in the Pan African Clinical Trials Registry up to 2018 shows that Egypt, with a total of 886 clinical trials, and SA, with 193, were the two countries with the highest number of registered clinical trials, but Nigeria ranked third with a total of 172 registered clinical trials. The number of clinical trials registered in Nigeria as shown in the continental Pan African Clinical Trials Registry is higher than in the more widespread ClinicalTrials.gov registry. Since Nigeria is the only country with a disparity in its position on the two clinical trials registries, and given that comparison of the results of the two registries indicates that a larger number of clinical trials are registered in the well-known ClinicalTrials.gov registry, only the ClinicalTrials.gov registry was used for further data analysis in this study.

Review of the number of clinical trials registered in the National Health Research Database in SA between 2010 and 2018 identified a total of 5374 registered clinical trials. Its Nigerian counterpart, the Nigeria Clinical Trials Registry, works only as a tool for submitting registrations to the Pan African Clinical Trials Registry and processes the comparatively low 172 trial registrations recorded there. Nigeria therefore does not have a specific database for clinical trials, and the National Health Research Database in SA is unable to cover the entire research period from 2010 to 2018, as the database has only been archived since 2013. As the two databases were not established and do not operate according to similar standards, no meaningful comparison of the data is possible, and only the ClinicalTrials.gov registry was therefore included in the final data analysis.

\section{Globalisation and trends in clinical trials in Nigeria and SA}

The trend lines in Fig. 1 show that Nigeria recorded a relative increase in the number of clinical trials from 2010 to 2018. In contrast, SA has been in a clear downward trend in the number of clinical trials started annually since 2010, even if absolute numbers are still four times higher than in Nigeria.

\section{Factors that may influence the clinical trials business in Nigeria and SA}

In identifying possible factors that might influence the clinical research business in Nigeria, various health data including demographic statistics were selected and compared with those in SA (Supplementary Table 1, available at http://samj.org.za/public/ sup/14870-t.pdf). Key differences in some factors were observed that may differently impact on the clinical trials business in the two countries, including population demographics, country-specific diseases, socioeconomic variables, and the nature of the regulatory framework/laws governing clinical trials, especially the time required to obtain approval for a clinical trial application. It is striking that Nigeria has three times as many inhabitants as SA, and that average life expectancy is 8 years shorter than that in SA. Nigeria also has a significantly higher proportion of children, and the mortality rate in children aged $<5$ years is nearly three times as high as that in SA. The number of women who die during pregnancy or childbirth is also significantly higher in Nigeria than in SA, with $814 \mathrm{v} .138$ deaths per 100000 live births. The frequent occurrence of specific diseases also plays a role here. In this context, malaria and leprosy have been identified as country-specific diseases in Nigeria, while SA has high incidences of HIV/AIDS and tuberculosis (TB) (Table 2). It could therefore be assumed that these diseases would be particularly frequently investigated in clinical studies, considering the availability of a large patient pool that means a fast recruitment process for any given study, which saves time, is cost-effective and suits the profitorientated business models of national and international sponsors. The less stringent regulatory laws in Nigeria, including the shorter time required to obtain approval for a clinical trials application, would also save time and reduce the cost of business. This factor may explain the current shift of international sponsors to Nigeria rather than SA under the globalisation process.

\section{Matching drug development research studies to the locally endemic diseases}

The list of the 10 fields of study most often researched in Nigeria and SA between 2010 and 2018 (Table 3) shows that communicable diseases and infections were most frequently researched in both countries. Similarly, clinical trials on HIV/AIDS were increasingly conducted in both countries. HIV/AIDS is one of SA's country-specific diseases, so it is not surprising that HIV/AIDS is a popular study area there. Surprisingly, TB, the second most common disease in SA, is not listed among the top 10 study areas in that country. In Nigeria, malaria is the only country-specific disease that is listed among the top 10 study areas, and leprosy is not included separately on the list.

\section{Assessing differences between local and international sponsors, both in number of clinical trials and indication areas}

A subsequent distinction was made between national and international sponsorship of clinical studies in the two countries. National sponsors were operationalised to include universities and

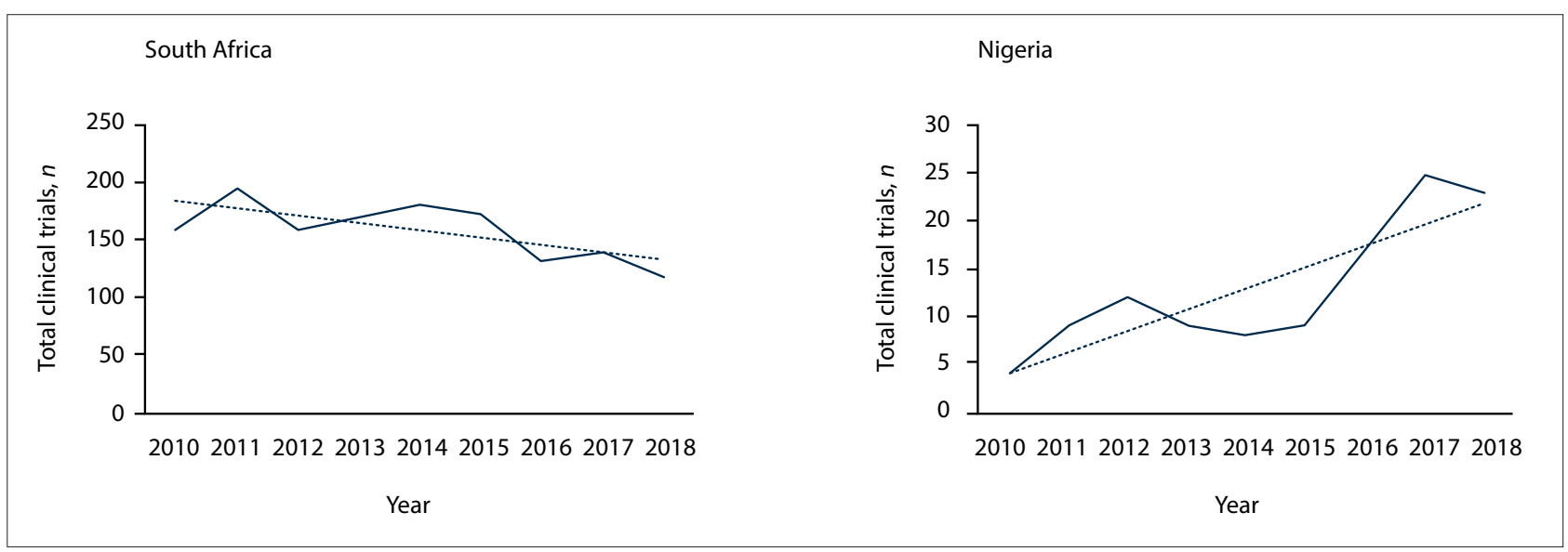

Fig. 1. Trends in clinical trials associated with globalisation. The solid lines represent the real development course according to the data sets, and the dotted lines help to visualise the upward or downward trend between the starting point and the endpoint of the research time period. 
hospitals, individuals, organisations and industries that are locally based in the country and conduct clinical trials (Supplementary Table 2, http://samj.org.za/public/sup/14870-t.pdf). International sponsors, as previously mentioned, are located outside the country where they conduct clinical trials, and include such agencies as the National Institutes of Health and other US federal agencies (Supplementary Table 3, http://samj.org.za/public/sup/14870-t.pdf). Supplementary Table 2 shows the number of clinical trials funded by national sponsors between 2010 and 2018, while Supplementary Table 3 shows the number funded by international sponsors. In $\mathrm{SA}$, the number of clinical trials funded by national sponsors generally increased between 2010 and 2018, while the number of internationally funded trials decreased during this time (Fig. 2). In Nigeria, however, the number of both nationally funded and internationally funded clinical trials increased (Fig. 3).

Sorting of the clinical trials into the country-specific diseases listed in the WHO fact sheets indicates that in SA, HIV/AIDS and TB are studied in both nationally and internationally funded trials, whereas

Table 1. Ranking of African countries according to the number of registered clinical trials in ClinicalTrials.gov

\begin{tabular}{ll}
\hline Country & Clinical trials, $\boldsymbol{n}$ \\
\hline Egypt & 2620 \\
South Africa & 2545 \\
Uganda & 464 \\
Kenya & 424 \\
Tanzania & 301 \\
Tunisia & 268 \\
Malawi & 208 \\
Zambia & 176 \\
Ghana & 146 \\
Nigeria & 145
\end{tabular}

Table 2. Comparison of country-specific diseases in Nigeria and South Africa, 2012

\begin{tabular}{lll}
\hline & \multicolumn{2}{c}{$\begin{array}{c}\text { Incidence rate, } \\
\text { /100 } 000 \text { population }\end{array}$} \\
\cline { 2 - 3 } & Nigeria & South Africa \\
\hline HIV/AIDS & 153 & 700 \\
Tuberculosis & 108 & 1003 \\
Malaria & 28710 & 33 \\
Neglected tropical diseases & 3805 & 15 \\
(new cases of leprosy) & &
\end{tabular}

in Nigeria, malaria is the only country-specific disease investigated by nationally and internationally funded studies. It was also observed that in Nigeria, national and international sponsors are focusing on studies on HIV/AIDS instead of leprosy.

It was considered reasonable that country-specific diseases should not be considered the only possible basis for an increased number of studies in the two emerging countries, Nigeria and SA. Other factors, such as differences between the regulatory framework of national authorities (Supplementary Table 4, http://samj.org.za/public/ sup/14870-t.pdf) and ethics committees (Supplementary Table 5, http://samj.org.za/public/sup/14870-t.pdf) of the two countries, should count as well. Based on the analysis, it is striking that the South African Health Products Regulatory Authority (SAHPRA) and/or the Medicines Control Council (MCC), as the national regulatory authority in SA, take an average of 60 - 80 working days to approve a clinical trial application. NAFDAC, Nigeria's national regulatory authority, takes 60 working days to approve a clinical trial application, although this may be longer in some cases. A further advantage for Nigeria could be the possibility of a scientific advice meeting and provision for personal presentation of the study to NAFDAC by the sponsors. This service is not offered by SAHPRA and/or the MCC in SA. Comparison of the ethical framework conditions of the National Health Research Ethics Council in SA and the National Health Research Ethics Committee in Nigeria shows that both countries have very similar ethical framework conditions except for shorter approval time for a clinical trial application of an average of 20 - 40 working days in SA compared with 60 working days in Nigeria.

\section{Discussion}

Comparison of the number of registered clinical trials in the ClinicalTrials.gov registry, maintained by the US National Library of Medicine, and the continental Pan African Clinical Trials Registry shows that trial registration is more frequent in ClinicalTrials.gov. It can therefore be assumed that many clinical trials by international pharmaceutical companies are not additionally registered in local national trial registries. From an ethical point of view, this could pose a hurdle for clinical trial participants, as the responsible pharmaceutical industry expects every participant to be familiar with the ClinicalTrials.gov registry and its functionality. In terms of user-friendliness and time efficiency, it would certainly be more convenient for participants in some developing countries to obtain all trial information in their own language from a national trial registry. Consequently, it would be ethically ambitious to force international pharmaceutical industries to additionally register their clinical trials in a national study registry if such exists. In this context, the increase in the local number of trial registrations in the

Table 3. Top 10 fields of study researched in South Africa and Nigeria

\begin{tabular}{llll}
\hline South Africa & Registered studies, $\boldsymbol{n}$ & Nigeria & Registered studies, $\boldsymbol{n}$ \\
\hline Communicable diseases & 348 & Communicable diseases & 33 \\
Infections & 348 & Infections & 33 \\
Immune system diseases & 319 & AIDS & 22 \\
AIDS & 268 & HIV infection & 22 \\
HIV infection & 268 & Malaria & 15 \\
Respiratory tract diseases & 209 & Parasitic diseases & 14 \\
Metabolic diseases & 186 & Protozoan infections & 14 \\
Viral diseases & 175 & Viral diseases & 14 \\
Lung diseases & 169 & Haematological diseases & 12 \\
Syndrome & 159 & Anaemia & 11
\end{tabular}




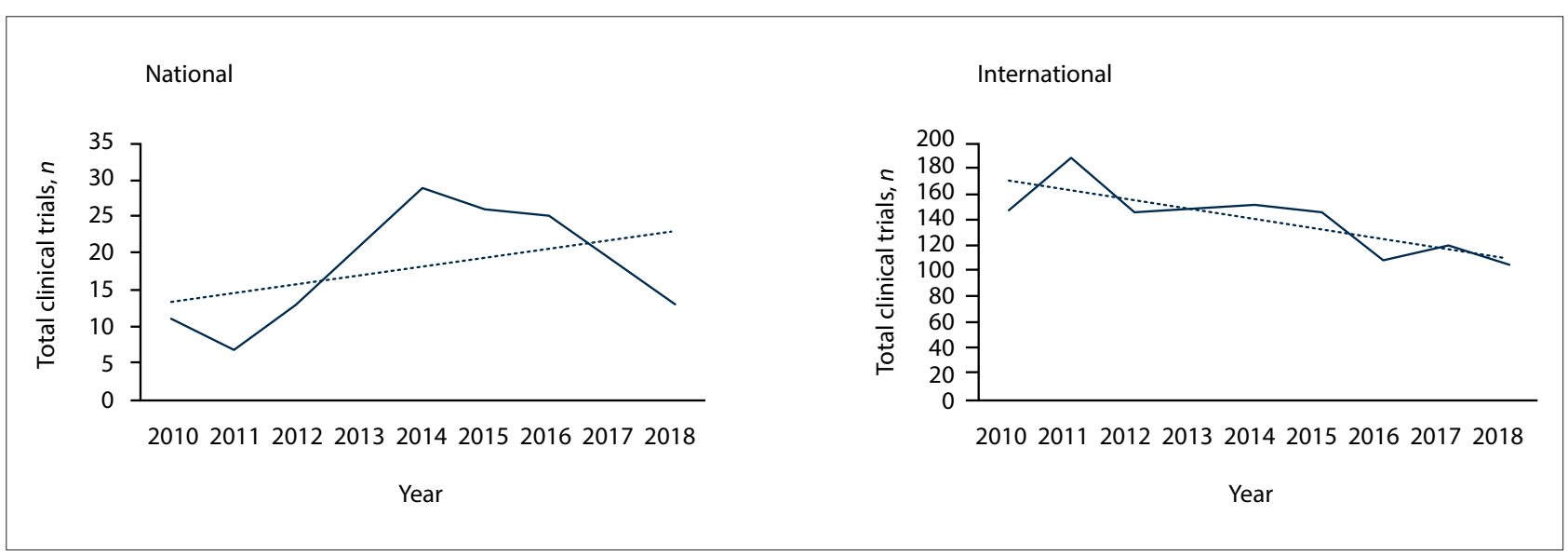

Fig. 2. National v. international sponsorship in South Africa. The solid lines represent the real development course according to the data sets, and the dotted lines help to visualise the upward or downward trend between the starting point and the endpoint of the research time period.

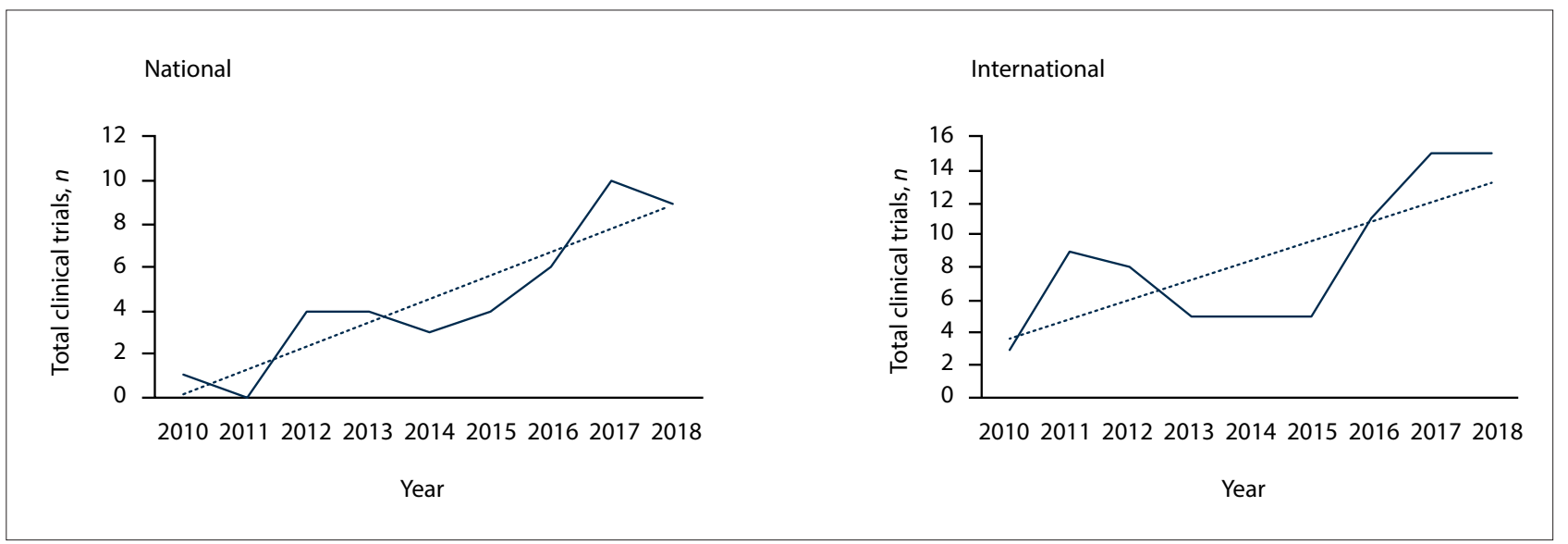

Fig. 3. National v. international sponsorship in Nigeria. The solid lines represent the real development course according to the data sets, and the dotted lines help to visualise the upward or downward trend between the starting point and the endpoint of the research time period.

National Health Research Database from 2013 to 2018 is striking, as is the simultaneous decrease in registrations in the ClinicalTrials. gov registry. These changes could signify a shift from internationally managed trial registries to nationally managed registries.

According to Glickman et al. ${ }^{[27]}$ (2009), 'clinical trials increasingly occur on a global scale as industry and government sponsors in wealthy countries move trials to less wealthy countries. This trend suggests that clinical research is undergoing the same globalisation process as other industries.' However, this process may not be the same for every emerging market. Fig. 1 shows that the assumed upward trend in SA has even turned into a downward trend in the last 8 years. So the globalisation trend in favour of the SA market is already over, and the country seems to have become less attractive for clinical trials despite its high clinical trial numbers. Even with this obvious downward trend, SA is still in second place in the ranking of African countries according to the number of registered clinical trials. On this basis, it may be speculated that $\mathrm{SA}$ is regarded as the country on the African continent that has made the most progress in its development and is most aligned with Western industrialised countries in some areas, so that appropriate medical care and sufficiently developed infrastructures are available to conduct clinical trials. This alignment with the Western industrialised countries could have been developed in the past years through some tightening of the regulatory laws governing the conduct of clinical trials in SA. SA's former advantage as a lesser-regulated clinical trial arena has therefore gradually turned into a disadvantage, in that the regulatory framework for conducting clinical trials is so aligned with those of the Western world that initiating a trial in SA is now just as timeconsuming, and therefore also as costly, as in the Western countries. The consequences of the westernised regulatory framework are also supported by an average approval time for a clinical trial application of 60 - 80 working days in SA, which may be one of several reasons for the decline in the number of clinical trials in SA.

A decline in the clinical trials trend in SA is more obvious when considering the number of registered studies on its country-specific diseases, HIV/AIDS and TB. The trend line diagrams show that clinical studies on HIV/AIDS and TB in SA are financed by national sponsors on the one hand, and international sponsors on the other. Given that the number of HIV/AIDS clinical trials in SA has been declining since 2015, unlike Nigeria, it is reasonable to infer that Nigeria is more attractive for the clinical research business. This view is plausible even though the country still ranks 10th among African countries in the number of registered clinical trials. This anomaly could be related to the fact that the clinical research business in Nigeria is still in its early stages of development. The regulatory and ethical frameworks necessary for the successful conduct of clinical trials have therefore only recently been adapted to the globally applicable Good Clinical Practice guidelines to abolish the 'bureaucratic, politically-influenced and lacking-in-transparency' review processes of research projects, which as Petros ${ }^{[28]}$ said, had 
previously been practised. For this purpose, the Association for Good Clinical Practice (AGCPN) in Nigeria was founded in 2005, which aimed to make Nigeria more attractive for conducting clinical trials. In 2012, the AGCPN held its first clinical trial summit to identify gaps in the clinical research industry in Nigeria and offer tailored strategic solutions, which have included lobbying governmental agencies to restructure their approach to clinical research. ${ }^{[29]}$ These positive efforts have affected the national regulatory authority - NAFDAC and the National Health Research Ethics Committee, which have set themselves a time limit of a maximum of 60 working days for the approval of a clinical trial application. Since the sponsor of a clinical trial can save a lot of time and money through these options, Nigeria appears to have become more attractive for sponsors than SA. All these beneficial regulatory changes could explain why Glickman et al. ${ }^{[27]}$ also hold the view that 'companies can realise substantial cost savings by conducting trials' in emerging countries. An increasing medical need for research on the various country-specific diseases that occur most frequently could be another possible reason for the growing attractiveness of emerging markets for conducting clinical trials. A direct comparison shows that in SA, both local and international sponsors are interested in researching country-specific diseases, except for TB, even if international interest does not seem to be as strong as expected. In Nigeria, the second-highest countryspecific disease, leprosy, has not attracted the interest of sponsors. Instead, a few HIV/AIDS studies have been conducted by national and international sponsors. Invariably, in conducting clinical research in the emerging markets, both national and international sponsors do not seem to prioritise the more prevalent country-specific diseases. This failure could be an indication that the underlying interests for most of the clinical studies in emerging countries are not related to the prevalent local health needs, but reflect the business priorities of the international sponsors. It could also be assumed that the research companies are more interested in non-communicable diseases, which could be regarded as international diseases. However, the overall rise in the number of studies done in Nigeria could indicate that the clinical research business has only just begun.

It was revealed that the number of HIV/AIDS studies in Nigeria has risen significantly since 2015. However, if one considers the decreasing trend in SA's return of HIV/AIDS-related clinical trials since 2015, with increasing numbers of such trials reported in Nigeria, the emerging picture suggests a shift in HIV/AIDS studies from SA to Nigeria. Since SA has the largest HIV epidemic in the world, with $19 \%$ of the global number of people living with HIV, 15\% of new infections and $11 \%$ of AIDS-related deaths, it is not surprising that 'South Africa has the largest treatment programmes in the world' and 'also has one of the largest domestically funded programmes, with about $80 \%$ of the AIDS response funded by the government. ${ }^{[30]}$ Awareness-raising work on HIV/AIDS in SA, through campaigns such as that of UNAIDS (the Joint United Nations Programme on HIV and AIDS), has brought the disease to people's notice and may be playing an important role in the substantial attention given to research on HIV/AIDS as a country-specific disease. The medical care of patients would have helped to contain the disease as well as to inform about possible ways of infection, and explore novel treatment options through clinical research studies. In Nigeria, on the other hand, medical care and awareness-raising efforts seem not to be as robust as in SA. The facts from the health data comparison suggest that healthcare in Nigeria has deteriorated considerably, as indicated by the shorter life expectancy and higher maternal and under-5 mortality rates compared with SA. Since the Nigerian population is three times larger than that of SA, and in addition to the lack of quality healthcare a sizeable baby boom prevails, it is even more difficult to implement awareness campaigns such as those of UNAIDS, which has also started its work in Nigeria. Given the observed scenario, it is plausible that either the Nigerian population is not yet enlightened enough to know that use of condoms can not only decrease the birth rate but also minimise infection with HIV/ AIDS, or there are other factors, such as religious beliefs, that hinder successful awareness raising. Nevertheless, since Nigeria has the second-largest HIV epidemic globally, it is not surprising that the patient pool there is large enough to conduct clinical trials on HIV/ AIDS. ${ }^{[31]}$ Miller et al. ${ }^{[32]}$ explain quite rightly that 'research should be responsive to the health needs of communities'. If, however, the medical needs should reflect the country-specific diseases mentioned in the fact sheets of the WHO, it is astonishing that in both SA and Nigeria only one of the country-specific diseases is included in the list of the top 10 study areas. However, this list also shows that most clinical trials were conducted in the field of communicable diseases in Nigeria and SA. Since the not explicitly mentioned country-specific diseases TB and leprosy (which belongs to the neglected tropical diseases) fall under the generic term communicable diseases, they are probably also the subject of clinical trials in the respective countries.

In addition to the growing medical need for research on countryspecific diseases, increasing capacity building may also be required in both countries. This does not only mean the building of medical care centres, such as hospitals, but also the fundamental improvement of medical care. The conduct of internationally sponsored clinical trials creates attractive opportunities that keep medical experts in the country, and according to Ali and Finlayson, ${ }^{[33]}$ also provides them with regular training opportunities that expand their medical expertise. This again benefits the population to be cared for. The term capacity building, in the business of clinical research, therefore covers several aspects and is also of importance for the development of clinical research in developing countries.

\section{Study limitations}

The following limitations of this study should be taken into account. Firstly, updated incidence rates were published in the WHO 2018 fact sheets after this article was completed. Secondly, only the internationally recognised database ClinicalTrials.gov for the registration of clinical trials was used to process the research question, whereas there are other local databases such as the National Health Research Database in SA, apart from the Pan African Clinical Trials Registry. These un-utilised databases may provide additional information on the trends in the business of clinical research in Nigeria and SA, but were not included in this study for reasons mentioned in the 'Methods' section.

\section{Conclusions}

\section{Implications for practice}

The findings of this study demonstrate that globalisation has an impact on the clinical trials arena in the emerging countries, especially Nigeria and SA. The findings indicate that there are several reasons why sponsors are increasingly having their clinical trials conducted in emerging markets such as SA and Nigeria. These reasons include an increased medical need for research into the various country-specific diseases that, owing to their high incidence rates, have a large pool of naive patient groups. This makes fast recruitment possible and translates to cost savings due to time saved. In Nigeria, the shortened processing time for the evaluation of a clinical trial application adds to the country's attractiveness as a profitable market for conducting clinical research compared with SA. It also explains why there has 
been a downward trend in the number of registered clinical trials in SA from 2010 to 2018 but an upward trend in the number in Nigeria. This finding is reinforced by the observation that while the number of local sponsors increased in SA, the number of international sponsors decreased over the same period. In contrast, both local and international sponsors increased in Nigeria. Other reasons, according to Clinical Research South Africa, ${ }^{[34]}$ include qualitative data provided quickly and affordably by qualified researchers, and the presence of genetically diverse population groups in a country. In emerging markets, a lower drop-out rate of clinical trial participants is also expected, as participation in a clinical trial is often the only option for good medical care. Nevertheless, the increasingly tight regulatory environment in SA makes it similar to the Western world, and for this reason sponsors will look more favourably towards Nigeria than SA when conducting clinical trials.

\section{Implications for research}

Further research relating to the annual trends in the number of registered clinical trials in the SA local database (the National Health Research Database) should be done to determine whether the local database, apart from the Pan African Clinical Trials Registry, reflects a similar trend in the business of clinical research to that reported in this study. SA may well be used as a case study in a further analysis to find out whether the number of trial registrations has increased annually between 2013 and 2018, and whether the introduction of the National Health Research Database has led to a shift of registrations from the international ClinicalTrials.gov registry to the national registry.

\section{Declaration. None.}

\section{Acknowledgements. None.}

Author contributions. VS conceived of the research and carried out the analysis. SCI contributed to the interpretation of the results. Both authors discussed the results and prepared the final manuscript.

Funding. None.

Conflicts of interest. None.

1. Novak T, Payeur G, Belotserkovsky M. Decline of clinical trials in Central and Eastern Europe Fluctuation or trend? Applied Clinical Trials, 16 June 2014. http://www.appliedclinicaltrialsonline.com/ decline-clinical-trials-central-and-eastern-europe-fluctuation-or-trend (accessed 9 August 2018).

2. Jeong S, Sohn M, Kim JH, et al. Current globalisation of drug interventional clinical trials: Characteristics and associated factors 2011 - 2013. Trials 2017;18(1):288. https://doi.org/10.1186/s13063-017-2025-1

3. Da Silva RE, Amorim Amato A, Guilhem DB, Carvalho Garbi Novaes MR. Globalisation of clinical trials: Da Silva RE, Amorim Amato A, Guilhem DB, Carvalho Garbi Novaes MR. Globalisation of clinical trials: ijct20160472

4. Alemayehu C, Mitchell G, Nikles J. Barriers for conducting clinical trials in developing countries a systematic review. Int J Equity Health 2018;17:37. https://doi.org/10.1186/s12939-018-0748-6

5. Lang T, Siribaddana S. Clinical trials have gone global: Is this a good thing? PLoS Med 2012;9(6):e1001228. https://doi.org/10.1371/journal.pmed.1001228
6. Boyd M. Journal discussion: Clinical research in low- and middle-income countries. Virtual Mentor 2009;11(7):511-515. https://doi.org/10.1001/virtualmentor.2009.11.7.jdsc1-0907

7. Wise J. Pfizer accused of testing new drug without ethical approval. BMJ 2001;322:194. https://doi. org/10.1136/bmj. 322.7280 .194

8. Organisation for Economic Co-operation and Development (OECD). DAC List of ODA Recipients Effective for reporting on 2011 flows. http://www.oecd.org/dac/financing-sustainable-development/ development-finance-standards/DAC\%20List\%20used\%20for\%202011\%20flows.pdf (accessed 21 April 2019)

9. Roser M, Ritchie H. Burden of disease. Our World in Data, 2016. https://ourworldindata.org/burden-ofdisease (accessed 26 March 2020).

10. Global Health Data Exchange, Institute for Health Metrics and Evaluation, University of Washington Global Burden of Disease Study 2017 (GBD 2017) results. http://ghdx.healthdata.org/gbd-results-tool (accessed 26 March 2020).

11. World Bank Group. Data - South Africa. 2019. https://data.worldbank.org/country/south\%20africa (accessed 26 March 2020)

12. World Bank Group. Country profile - South Africa. 2019. https://databank.worldbank.org/views/ reports/reportwidget.aspx?Report_Name=CountryProfile\&Id=b450fd $57 \&$ tbar $=y \& d d=y \& i n f=n \& z m=n$ reports/reportwidget.aspx?Report_Name=C
\&country=ZAF (accessed 26 March 2020).

13. World Bank Group. Data - Nigeria. 2019. https://data.worldbank.org/country/nigeria (accessed 26 March 2020).

14. World Bank Group. Country profile - Nigeria. 2019. https://databank.worldbank.org/views/reports/ reportwidget.aspx?Report_Name=CountryProfile\&Id=b450fd57\&tbar=y\&dd=y\&inf=n\&zm=n\&count $\mathrm{y}=\mathrm{NGA}$ (accessed 26 March 2020).

15. Odunuga M. Nigeria is the 26th largest economy in the world and Africa's biggest economy ConnectNigeria.com, 7 April 2014. https://connectnigeria.com/articles/2014/04/nigeria-is-the-26thlargest-economy-in-the-world-and-africas-biggest-economy/ (accessed 27 March 2020)

16. US National Library of Medicine, National Institutes of Health. ClinicalTrials.gov. https://clinicaltrials. gov/ (accessed 21 April 2019).

17. Pan African Clinical Trials Registry (PACTR). https://pactr.samrc.ac.za/ (accessed 30 April 2019).

18. National Department of Health, South Africa. The National Health Research Database (NHRD). https:// nhrd.hst.org.za/ (accessed 15 May 2019).

19. Federal Ministry of Health, Nigeria Clinical Trials Registry http://nctrnhrec net/ (accessed 20 May 2019).

20. World Health Organization, Regional Office for Africa. South Africa - Factsheets of Health Statistics 2016. WHO, 2018.

21. World Health Organization, Regional Office for Africa. Nigeria - Factsheets of Health Statistics 2016 WHO, 2018.

22. National Department of Health, South Africa. South African Good Clinical Practice Guidelines. 2nd ed. 2006. http://www.kznhealth.gov.za/research/guideline2.pdf (accessed 23 April 2019).

23. National Institute of Allergy and Infectious Diseases, National Institutes of Health. ClinRegs: Aggregating clinical research regulations from around the globe: South Africa. https://clinregs.niaid.nih.gov/country/ south-africa (accessed 23 May 2019).

24. National Agency for Food \& Drug Administration \& Control, Drug Evaluation \& Research Directorate. Guidelines for Clinical Trial Application in Nigeria. 2019. https://www.nafdac.gov.ng/wp-content/ uploads/Files/Resources/Guidelines/DRUG_GUIDELINES/GUIDELINES-FOR-CLINICAL-TRIALAPPLICATION367.pdf (accessed 23 April 2019).

25. National Department of Health, South Africa. Ethics in Health Research: Principles, Processes and Structures. 2015. http://nhrec.health.gov.za/index.php/grids-preview (accessed 23 April 2019).

26. National Health Research Ethics Committee, Federal Ministry of Health, Nigeria. National Code of Health Research Ethics. August 2007. http://nhrec.net/download-nchre/ (accessed 23 April 2019).

27. Glickman SW, McHutchison JG, Peterson ED, et al. Ethical and scientific implications of the globalisaGlickman SW, McHutchison JG, Peterson ED, et al. Ethical and scientific implications of the globalisa-
tion of clinical research. N Engl J Med 2009;360(8):816-823. https://doi.org/10.1056/NEJMsb0803929

28. Petros B. Ethical review of health-related biotechnology research in Africa: A role for the Pan African Petros B. Ethical review of health-related biotechnology research in $A$
Bioethics Initiative (PABIN). Afr J Med Med Sci 2007;36(Suppl):43-47.

29. Association for Good Clinical Practice in Nigeria. Our History. 2019. http://agcpng.com/aboutu (accessed 23 April 2019).

0. UNAIDS (Joint United Nations Programme on HIV and AIDS). South Africa: Overview. 2019. http:// www.unaids.org/en/regionscountries/countries/southafrica (accessed 23 April 2019).

1. UNAIDS (Joint United Nations Programme on HIV and AIDS). Nigeria: Overview. 2019. http://www. unaids.org/en/regionscountries/countries/nigeria (accessed 23 April 2019).

32. Miller L, Folayan M, Allman D, et al. How ethical is your clinical trial? Int J Clin Pract 2010;64(9):11791182. https://doi.org/10.1111/j.1742-1241.2010.02421.x

33. Ali R, Finlayson A. Building capacity for clinical research in developing countries: The INDOX cancer research network experience. Glob Health Action 2012;5(1):17288. https://doi.org/10.3402/gha. v5i0.17288

34. Clinical Research South Africa. What do international sponsors want? http://www.clinicalresearchza. com/pharmaceutical_companies_international_sponsors.html (accessed 23 April 2019). 